\title{
SOR JUANA: NUEVOS HALLAZGOS, VIEJAS RELACIONES
}

\author{
Sara POOT HERRERA \\ University of California, Santa Barbara
}

A Enrique Martínez López

Hace más de 300 años murió sor Juana Inés de la Cruz. Y no sólo renace de sus cenizas en calidad de ave fénix sino que - rara avis in terris - cobra magna relevancia en la última década de nuestro siglo. Poeta de gran fama en su época - dentro y fuera de la Nueva España — su obra rebasa su siglo y se instaura en las primeras líneas de interés de los estudios sobre el barroco español, la poesía novohispana, y qué decir de la literatura femenina del siglo XX de la que no sólo se convierte en antecedente imprescindible sino que tiene en ella firme presencia y contemporaneidad.

El interés actual sobre sor Juana Inés de la Cruz se enriquece con los recientes hallazgos que giran en torno de su vida y su obra. Varios de ellos son atisbos no de nuevas sino de viejas relaciones; algunas de estas relaciones se podrían ver ahora de distinta manera a como se vieron durante muchos años. A los inmediatos a la muerte de sor Juana - 17 de abril de 1695-, a los que siguieron a la publicación de la Fama y Obras pósthumas en 1700 y a los que antecedieron precisamente a hallazgos recientes: piezas que junto con otros escritos dan lugar en sí mismos y en su conjunto a nuevas lecturas e interpretaciones sobre la vida y la obra de sor Juana Inés de la Cruz.

Entre esos escritos hay varios libros importantes publicados en este siglo. Anteceden a la efervescencia actual del interés por la Décima Musa mexicana; 
iluminan sobre su vida, su obra y el contexto donde vivió y escribió. Mencionaremos algunos de ellos. En 1910, Amado Nervo dio a conocer en Madrid su Juana de Asbaje. De mitad de siglo - 1951-1957- es la excelente edición de las Obras completas de Sor Juana Inés de la Cruz, iniciada y llevada a cabo en gran parte por Alfonso Méndez Plancarte y concluida por A. G. Salceda. En 1966 Francisco de la Maza fechó su preámbulo de Sor Juana Inés de la Cruz ante la historia (Biografias antiguas. La Fama de 1700. Noticias de 1667 a 1892), publicado en 1980. Sor Juana Inés de la Cruz o Las trampas de la fe de Octavio Paz y Humanismo y religión en Sor Juana Inés de la Cruz de Marie-Cécile Bénassy Berling inauguraron a principios de los ochenta una nueva época en el ámbito de los estudios de sor Juana y el siglo XVII.

En el tercer centenario de su muerte se realizaron varios homenajes sobre sor Juana y su siglo, antecedidos en la época actual por uno que pocos años antes celebraba un aniversario más de su nacimiento; me refiero al de noviembre de 1991 que organizó el Programa Interdisciplinario de Estudios de la Mujer de El Colegio de México. Dio lugar al volumen colectivo «Y diversa de mí misma / entre vuestras plumas ando». Homenaje internacional a Sor Juana Inés de la Cruz. En 1995, sobre el siglo XVII y sor Juana en el centro, apareció Sor Juana y su mundo. Una mirada actual, y se publicaron las ediciones facsimilares de la Carta Atenagórica (1690), Inundación Castálida (1689), del Segundo volumen de sus obras (1692) y de la Fama y Obras Pósthumas (1700). A estos libros multiplicados asombrosamente se unen documentos que ofrecen nuevos aportes sobre tan afamada escritora novohispana.

Son documentos que amplían la lista de inéditos sorjuaninos anunciados por el editor de la Fama y Obras pósthumas de Sor Juana Inés de la Cruz, cinco años después de la muerte de la escritora. Los últimos treinta años de este siglo, a los que nos vamos a referir, ofrecen testimonios «reales» a los estudios sobre la décima musa mexicana debido a algunos documentos encontrados en Portugal, en México, en los Estados Unidos y en España. A partir de estos testimonios, los estudios sobre sor Juana y su época cuestionarán y exigirán cada vez más lecturas basadas sobre todo en documentación histórica que es la que en los últimos tiempos, y como una nueva etapa de estudios sobre la Nueva España, proporciona bases más firmes para el análisis y la interpretación.

Ubico estos hallazgos entre 1968 -año en que se dio a conocer un «librito» armado entre sor Juana, la condesa de Paredes y ocho monjas portuguesas, cuyo contenido eran veinte enigmas de autoría sorjuanina- y 1997 - año de publicación del Catálogo de textos marginados. Inquisición: siglo XVII, que ofreció fuentes y piezas de un proceso inquisitorial que había involucrado el nombre de sor Juana Inés de la Cruz, y año de la celebración del coloquio Sor Juana \& Vieira, trescientos años después, en el que se dieron a conocer relaciones interesantes alrededor de los últimos años de sor Juana. La publicación de las actas de 
este coloquio - 1998 - marca, entre otros, un momento importante de reflexión sobre los hallazgos en torno a sor Juana Inés de la Cruz. Los hallazgos de estos treinta años constatan la presencia de personajes relacionados - para bien o para mal- con la monja novohispana, poeta de todas las épocas. Partamos de 1968.

Los Enigmas ofrecidos a la discreta inteligencia de la soberana Asamblea de la Casa del Placer, por su más rendida y aficionada Soror Juana Inés de la Cruz, Décima Musa fueron localizados por Enrique Martínez López en la Biblioteca Nacional de Lisboa. Los dio a conocer en el Tercer Congreso Internacional de Hispanistas celebrado en El Colegio de México y los publicó en la Revista de Literatura de Madrid con el título de «Sor Juana Inés de la Cruz en Portugal: un desconocido homenaje y versos inéditos». Con base en este hallazgo conocido en México en 1968, Antonio Alatorre publicó 26 años después su edición y estudio de sor Juana Inés de la Cruz, Enigmas ofrecidos a La Casa del Placer. A los dos manuscritos hallados por Martínez López, Alatorre añadió otros dos que él localizó; los cuatro pertenecen a la Biblioteca Nacional de Lisboa'.

Se trata de veinte Enigmas literarios escritos en forma de redondillas; los acompaña la «Dedicatoria» que, en un romance de 64 versos, dedica la monja jerónima a las monjas portuguesas de varios conventos: «A vuestros ojos se ofrece/este libro, por quedar/ilustrado a tanto sol/digno de tanta deidad» (vs. 1-4). Después del romance -que en tres versos se refiere textualmente al «libro»-, hay un soneto también de sor Juana, que funciona a manera de «Prólogo»: «Este volumen, cuyo altivo aliento/- benévolo lector siempre invocado- (vs. 1-2). La dedicatoria que anuncia «este libro» y el prólogo que menciona «este volumen» advierten sobre un proyecto de publicación entre las monjas portuguesas y la monja mexicana; proyecto que casi seguramente fue «De la Excelentísima Señora Condesa de Paredes, Visreina que fue en México, y particular aficionada de la autora». De ella es un romance de 56 versos - parte medular de los escritos que anteceden a las redondillas de la poeta-, en el que menciona como «libro» los enigmas de sor Juana: «Amiga, este libro tuyo/es tan hijo de tu ingenio,/que correspondió, leído/a la esperanza, el afecto»; «A ti misma te excediste,/pues este libro que veo/cuasi que sería malo,/si aun no fuera más que bueno» (vs. 1-4 y 912). La condesa, presente en el primer libro de sor Juana en España, con un romance propio aparecía ahora en Portugal en un libro que tal vez sería el último fechado en vida de su amiga.

A su romance lo acompañan otros poemas. Antes, unas endechas endecasílabas «A la autora, por Soror Mariana de Santo Antonio, religiosa en el monasterio de Santa Clara», quien también en tres versos menciona el libro que «A sagradas deidades» se ofrece y que «Tan alto amparo» busca (vs. 21 y 25). Después del

I De uno y otro investigador tomo la información y los datos sobre los Enigmas de sor Juana; para las citas textuales, utilizo la edición de Martínez López (1968). 
romance de la condesa, aparece un romance de arte mayor «A la autora, de Soror Francisca Xavier, religiosa en el convento de la Rosa», quien menciona este «corto libro» y le dice a su autora: «porque en tu auxilio logre felizmente/tan noble ofrenda, protección tan noble» (vs. 39-40); y otras endechas endecasílabas «A la Décima Musa, de Doña Simoa de Castillo, religiosa en el monasterio de Santa Ana», quien se refiere también a «tan alta protección» (v. 24). Son sendos poemas en español de tres monjas portuguesas quienes, como la exvirreina, también aluden al ofrecimiento a «sagradas deidades», «deidades superiores», «sacro numen» y a «sus altares»; las religiosas y la condesa coinciden con la autora quien dedica el libro a «tanta deidad». Sor Juana, antes que nadie y como siempre, marca las intenciones de sus escritos, en este caso, de los enigmas. Dice en su «Dedicatoria»: «Divertiros sólo un rato/es cuanto podrá aspirar/que fuera mucho emprender/atrevérselo a ocupar» (vs. 5-8). Y, así, ofrece a las monjas como ella un ingenioso entretenimiento literario, de salón, podríamos decir.

Y para que los Enigmas sean un libro con todas las de la ley, se avalan en Portugal con dos censuras y tres licencias, todas de autoría femenina. Primero aparece la «Censura da Senhora D. Feliciana de Milão, religiosa no convento de Odivelas». Sus primeras palabras son: «Por soberano decreto li os enigmas que se incluiem neste breve e misterioso volumen»; las firma la religiosa en «Odivelas, 26 de Janeiro de 1695». La segunda es la «Censura da Senhora D. Maria das Saudades, religiosa no convento de Vialonga», quien escribe:

Posso juntamente dizer que êste livro, que me manda ler alto preceito... me parece que êstes enigmas, principalmente afiançados não menos que na proteção de tantas e tão sup[e]riores divindades, são dignos de que na Casa do Prazer, esfera de mais luzidos astros, se leiam e se interpretem... mas as mesmas divindades que amparam a obra que indignamente censuro... Vialonga, 28 de Janeiro de 1695.

La censura de D. Maria das Saudades reafirma que el texto es un libro; que la lectura para su licencia se ha solicitado por «alto precepto»; que los enigmas de sor Juana «afianzados nada menos que en la protección de tantas y tan superiores divinidades» van a ser leídos en la «Casa del Placer» por las mismas divinidades que ahora los amparan.

Después de las dos censuras aparecen las tres licencias, escritas en décimas poéticas. La primera «que toca à fé» es de soror María Magdalena del convento del Calvario. La licencia explicita el carácter de divertimento adivinatorio en la lectura de los enigmas: «Pode êste livro passar,/de todo o castigo isento,/que em justo divertimento/ñao é culpa adivinhar» (vs. 1-4). La segunda licencia «que compete à Jurisdisçao Real» es de D. Maria do Céu, religiosa del convento de la Esperança: «Pode êste livro correr,/que ñao tem nenhum defeito,/pois da casa do respeito/passa à Casa do Prazer» (vs. 1-4). Dice su autora que el libro no necesita corrección, «pois teve tanta atenção,/que só por ñao fazer mal/à jurisdição real,/ 
busca real proteção» (vs. 7-10). La última licencia «que pertence aos bons costumes» es de D. Maria Guedes, religiosa de Santa Mónica. La décima comienza con «É tanta a sua atenção/e dêste livro o concêrto,/que por ditado do acêrto/ o pode ser da razão» (vs. 1-4). Las tres licencias aprueban «este livro», refiriéndose a los «Enigmas da freira de México, em redondilhas, e são vinte».

A excepción del primer manuscrito de 1716, donde se localiza una copia de los enigmas, en los otros tres hay un «Index dos sacríficios que oferece a Poesia aos sagrados oráculos que ilustrarem as obscuridades dêstes enigmas»; son títulos de veinte composiciones poéticas distintas (un soneto, dos octavas, un romance de arte mayor...) que corresponden a cada uno de los enigmas y que responderían a las veinte preguntas que se inician de la misma manera: «¿Cuál es...?», «¿Cuál será...?», «¿Cuál puede...?», «¿Cuáles serán...?», «¿Cuál podrá...?» Sólo en un caso -enigma 14 aparece un sustantivo antes del verbo, «¿Cuál dolor puede ser?», para evitar el mismo principio del enigma 3 , «¿Cuál puede ser el dolor?» Sor Juana en la «Dedicatoria» de sus enigmas solicita a las monjas «no daros qué discurrir,/sino sólo qué explicar» (vs. 15-16). Y, al decir de Martínez López, las respuestas a las veinte preguntas son definiciones sobre el amor. Los enigmas serán motivo de una y otra lectura, de propuestas, de un juego literario, un pasatiempo muy entretenido.

Más allá del valor literario de estos enigmas —cuyo primer manuscrito conocido hasta la fecha es precisamente la copia de 1716, 21 años después de haber sido aprobados para su circulación y 21 años también de haber muerto sor Juana--, su importancia consiste sobre todo en saber que hubo relaciones literarias entre la monja mexicana y las monjas portuguesas. Religiosas de ocho conventos distintos — dos de ellas, sor Feliciana de Milao y Maria do Céu, «de renombre en las letras lusitanas» (Martínez López 1968, p. 57)—, están involucradas en este proyecto. A fines de enero de 1695 se fechan las dos censuras, eso es, a principios de ese año estaba listo como libro - breve, sí, pero redondo, completo: con dedicatoria, el romance de sor Juana; un prólogo, su soneto; cuatro agradecimientos como homenaje, los tres poemas de tres religiosas y el de la condesa de Paredes; las dos censuras en prosa y las tres licencias en décimas, también de religiosas; las veinte redondillas - los enigmas de sor Juana, núcleo del libro- y el índice de veinte nombres de composiciones poéticas. Aunque breve, el libro se multiplica al leerse; un enigma dará que pensar, y éstos son veinte.

Cada participante en el juego propondrá su propia respuesta; oirá la propuestas de los otros participantes. Además, hay veinte sugerencias para responder; ¿habría que escribir un poema o encontrar uno ya existente - de la propia autora, por ejemplo- para cada respuesta? La poeta ha discurrido un juego poético y para jugarlo hay qué explicar cada disquisición; habrá que conocer o hacerse de reglas para participar. Es un juego para jugarse una y otra vez. La brevedad del 
libro se multiplicará en su circulación, en su lectura de esparcimiento individual y, sobre todo, colectivo. Es un libro para abrir, cerrar, volver a abrir; circularía en sí mismo, entre las monjas, entre los conventos. Su carácter giratorio semejaría un torno conventual ${ }^{2}$; que gira, que da vueltas, que da, que recibe, que vuelve a girar. Los Enigmas reunirían a su alrededor a las nobles y letradas «freiras» de La Casa del Placer, o a las de los distintos locutorios conventuales - sin que se vieran entre sí las monjas de distintos lugares- adscritos a esa Casa del Placer, al que ahora los engarzaba más un torno literario.

Igual que sor Juana, cada monja participó desde su respectivo convento en el diseño del libro como tal; de la Excelentísima condesa de Paredes se dice en ese momento que fue virreina de México; o sea, son escritos posteriores a su estancia en la Nueva España. Con los datos que se tienen no podría fijarse a ciencia cierta la fecha de autoría de los enigmas; lo que sí podría asegurarse es que sor Juana los escribió expresamente para las monjas portuguesas y casi podría asegurarse que la condesa de Paredes se los pidió para que fuera un libro con patente y factura femeninas. Los 20 poemas de nuestra monja, los poemas con los que le responden sus destinatarias, las aprobaciones para la publicación de los textos, marcan un momento de filiación femenina entre Portugal, España y la Nueva España, significativo en los últimos años de sor Juana. Sobre todo si tenemos en cuenta los problemas que tuvo con la publicación de la Carta Atenagórica a fines de 1690.

Es muy posible que en este proyecto tuviera que ver, aunque tácitamente, la duquesa de Aveiro nombrada - lo mismo que la exvirreina- en la Respuesta que la poetisa firmó el primero de marzo de 1691. La genealogía femenina que construye sor Juana en su Respuesta deriva en sus amigas, la condesa de Paredes y la duquesa de Aveiro3; algunas de las monjas portuguesas de La Casa del Placer serían parte de tal genealogía. Estamos hablando de los años que se aproximan a la fecha que figura en el libro: 1695 , el año del fallecimiento de su autora. Hasta sus últimos días sor Juana mostraría el genio de su poesía. Los Enigmas son testimonio; la condesa de Paredes, de principio a fin, su aficionada número uno, la intermediaria Real e ideal entre la escritora y sus nuevos lectores.

Se sabía que la amistad entre ellas se había iniciado a la llegada de la virreina a la Nueva España en el marco de bienvenida del Neptuno Alegórico de noviembre de 1680 , el grandioso arco triunfal ideado por la monja, ya autora en esos días de varios juegos de villancicos. Se sabía también que la exvirreina dio a conocer a sor Juana al mundo de las letras al publicarle en España su obra, en la que la escritora le ofrecía inigualables piezas poéticas de agradecimiento y amistad. Lo

La idea del «torno» se la debo al profesor Martínez López a quien de inmediato se le ocurrió al yo mencionarle lo de «libro giratorio».

Sobre las mujeres nobles en torno de sor Juana, véase Sabat de Rivers 1993. 
que se sabe ahora - gracias primero a Enrique Martínez López y después a Antonio Alatorre - es que con los enigmas ofrecidos a La Casa del Placer sor Juana y la condesa de Paredes sellaban un lazo más de compromiso y amistad. Fueron escritos exclusivamente para las monjas portuguesas por parte de la poeta mexicana; posibles gracias a la lealtad de la condesa española. Si la exvirreina promovió en España la primera publicación de las obras de sor Juana, estando la poeta viva, casi podríamos afirmar que años después promovió en Portugal este libro que circularía selectivamente entre las monjas de La Casa del Placer; fuera ésta un lugar físico - un locutorio, un definitorio, una academia - de reuniones literarias o una asociación cultural, y literaria también, a la que pertenecerían desde sus respectivos conventos las monjas cultas de Portugal.

Menos de tres meses después de la aprobación de los Enigmas, murió sor Juana. La discreción de su escritura y de su recepción inicial, y el desconocimiento posterior de esas redondillas persistió hasta nuestro siglo. Nadie dijo nada de ellos al publicarse en 1700 en Madrid la Fama y Obras pósthumas de Sor Juana Inés de la Cruz. Tenía razón Donna Feliciana de Milão, cuando en su censura de los Enigmas calificó de «breve e misterioso volume» donde éstos estaban incluidos. Ese misterio es parte de episodios no aclarados ni resueltos de la vida de sor Juana. Otros hallazgos seguirían a este que hace más de treinta años tuvo lugar en Portugal.

Casi doce años después de que se dieran a conocer en la ciudad de México esos Enigmas, el padre Aureliano Tapia Méndez encontró una copia de la Carta de la Madre Juana lnés de la Cruz escripta al R. P. M. Antonio Núñez de la Compañía de Jesús, de la que antes tampoco se sabía absolutamente nada. El hallazgo ocurrió en abril de 1980 en la Biblioteca del Seminario Arquidiocesano de Monterrey, Nuevo León, México. Por esta carta —uno de los más extraordinarios documentos hallados en los últimos años- se supo que sor Juana fue quien despidió a su confesor, el padre Antonio Núñez de Miranda; contrariamente a lo que siempre se había sabido, o sea, que el jesuita se había despedido de ella. La despedida ocurrió alrededor de 1682 - precisión de Alatorre (uso su edición)—, dos años después de que sor Juana ofreciera a los virreyes de la Laguna su mejor tarjeta de presentación: el texto del arco triunfal de bienvenida, denominado Neptuno Alegórico (1680). Si a partir de ese momento se marcó —y para siempre- la amistad entre sor Juana y la virreina, antes y durante más de una década sor Juana estuvo relacionada con el padre Núñez de Miranda, quien sería su confesor; jesuita de gran importancia de la época, hombre de letras y de gran poder en la capital de la Nueva España ${ }^{4}$.

4 Véase su biografía escrita por Juan Antonio de Oviedo, 1702. 
En 1669, el padre Núñez celebró la entrada de sor Juana Inés al convento de San Jerónimo - antes, comprendió que ella dejara la orden de las carmelitas en la que sólo permaneció tres meses-, estuvo cerca de ella durante los años setenta -época de los primeros villancicos de sor Juana, algunos publicados en forma anónima - y lejos de ella en los ochenta, la mejor década —al decir de Octavio Paz- de la creación poética de sor Juana. La «carta de Monterrey» cambió la perspectiva de la relación entre la monja jerónima y el padre jesuita. Sor Juana le reclama en su carta que él —de gran autoridad y prestigio— esté hablando mal de ella; la autoridad de las palabras del padre desacreditaba el nombre de la religiosa. Sor Juana le dice en su carta que primero decidió guardar silencio pero que ya es inadmisible su enojo, y todo - le dice- por «la facilidad» de los versos que todos saben que ella tiene. Concretamente se refiere al Arco de la Iglesia, esto es, al Neptuno Alegórico que compuso dos años antes. Menciona «los aplausos y celebraciones» que recibe. ¿Los solicitó acaso?, pregunta. Se detiene en los «particulares favores y honrras de los Excelentísimos Sres. Marqueses». ¿Son su culpa? ¿Acaso ella los ha buscado? Sor Juana defiende el derecho al estudio, su libertad, su libre albedrío, el «genio» de su escritura. Agradece el apoyo del jesuita - pagarle, por ejemplo, las clases de latín - pero le recuerda que él no decidió su entrada al convento ni puede obligarla a seguir el camino de la santidad. Le dice también que él no es la única vía de relación con Dios y que si no es para favorecerla que se olvide de ella.

Sor Juana aclara muy bien que el enojo de Núñez es por los versos, «negros versos» con los que el cielo la dotó. Que la ayuda de Núñez se ha convertido en «vituperios». Que en las conversaciones de Núñez sólo salen las culpas de sor Juana y el celo de él por la conversión de ella. Sor Juana, más allá de las preguntas retóricas que hace, pregunta textual y valientemente: «iSoi por ventura herege?» (1s. 227-228); «En qué se funda, pues, este enojo, en qué desacreditarme, en qué ponerme en concepto de escandalosa con todos? ¿Canso yo a V. R. con algo?» (1s. 236-238); «¿Qué precisión ay en que esta salvación mía sea por medio de V. R.?» (1s. 294-295). Y va contestando sus preguntas quitando peso y autoridad a Núñez quien no sólo tenía autoridad y peso sobre ella sino que tenía voz y voto en el Santo Tribunal de la Inquisición.

Estamos hablando de la década de los años ochenta. Sor Juana está muy bien relacionada con la corte; Núñez, menos, pero sí lo está con sus estudiantes de teología - uno de ellos es Alonso Alberto de Velasco, con sede en catedral-, con

$5 \quad$ En noviembre de 1980 en el periódico Excélsior de México el padre Tapia Méndez hizo del conocimiento público esta carta ofreciendo algunos de sus fragmentos. El padre Tapia Méndez tituló su primera edición Autodefensa espiritual de Sor Juana; la segunda, "Carta de Sor Juana Inés de la Cruz a su confesor». Autodefensa espiritual; la tercera es una edición de lujo con prólogo de Octavio Paz, Carta de Sor Juana Inés de la Cruz a su confesor. Autodefensa espiritual. Véase la excelente edición de Antonio Alatorre (1987) que titula «La Carta de Sor Juana al P. Núñez». 
sus compañeros inquisidores - algunos de ellos, alumnos también, como el dominico Agustín Dorantes-, con otras autoridades eclesiásticas; léanse personajes imprescindibles, nada menos que con el arzobispo de México, don Francisco de Aguiar y Seixas, y el obispo de Puebla, don Manuel Fernández de Santa Cruz.

Un triángulo empezó a cerrarse alrededor de sor Juana: Núñez, que de ser su confesor en los setenta - corrector de algunos de sus villancicos- pasó por su falta de caridad y discreción, según ella, a ser su exconfesor en los ochenta; quería que las monjas estuvieran muertas al mundo, y sor Juana estaba más que despierta en el mundo iluminado de su poesía y conocimiento. Aguiar, de cuyo arzobispado - a partir de los ochenta - dependía el convento de San Jerónimo y podía allanar —de haber querido - sus moradas interiores; fue famoso entre otras cosas porque odiaba el teatro, género en el que sor Juana era un portento; Fernández de Santa Cruz, que - cobrando presencia en los noventa- aprobó en Puebla la publicación de la Carta Atenagórica; tomó los hábitos trinitarios de Filotea de la Cruz y reprendió a sor Juana a la vista de todos. Tres personas «distintas» y una hija verdadera. El triángulo se estrecharía en los noventa, año que se cerraría con la publicación de la Carta Atenagórica. Pero en los ochenta, después de la llegada de la condesa de Paredes a la Nueva España y después de que sor Juana se despidiera de su confesor, se derramaría miel sobre hojuelas, las hojas de la poesía de quien empezaba a ser décima musa. Después del arco triunfal, vendría el gran momento de sor Juana Inés de la Cruz.

Lo recogió en Inundación Castálida la exvirreina de México, la condesa de Paredes, quien hizo llegar a España el libro. Las relaciones literarias de sor Juana se ensancharon. Dio su aprobación para que se publicara el libro quien le llamó precisamente rara Avis in terris: el viejo cura premonstratense, fray Luis de Tineo Morales. Eso fue en Madrid el 20 de agosto de 1689; ese mismo año y en ese lugar salió la primera edición del primer libro de sor Juana. Es la primera relación que encontramos entre sor Juana y fray Luis de Tineo. La segunda la proporciona otro de los hallazgos de los últimos años: «Un soneto desconocido de Sor Juana», que Antonio Alatorre dedicó a Octavio Paz en sus 70 años.

Se trata de un «Soneto/de cierta señora, Décima Musa», léase sor Juana, localizado en 1984 por Antonio Alatorre, al igual que el «Soneto/en respuesta al soneto antecedente» (Alatorre 1984, p. 12). Los dos fueron encontrados por Alatorre en el Gallardo de su propiedad: el Ensayo de una biblioteca española de libros raros y curiosos, formado con los apuntamientos de don Bartolomé José Gallardo (Alatorre 1984, p. 4). El primer soneto es de la monja novohispana; el que contesta, del fraile español; los dos entrarían en la nomenclatura de «sonetos satírico burlescos», aunque ni se satiricen o burlen entre sí. Eso sí, son ingeniosos y están llenos de gracia. Uno contesta al otro: si la primera línea del soneto de sor Juana dice: «Érase un preste cara de testuz», la primera línea del de Tineo contesta: «Aunque preste, jamás presté el testuz», y en ese tono y con las mismas 
rimas continúan los siguientes versos. A la última línea del soneto de sor Juana, «de Abades y de Prestes fiel espejo», Tineo contesta: «bien que sois de Camila fiel espejo» (Alatorre 1984, p. 12). Este verso que Tineo dedica a sor Juana, comparándola con la virgen guerrera virgiliana, cobrará más relevancia a la luz de otros hallazgos más recientes.

El que le sigue a éste de 1984 es de naturaleza distinta. A diferencia de los dos aquí anotados, es una pieza teatral. Castorena y Ursúa, al editar la Fama y Obras pósthumas en 1700, se refirió al final de un poema de Agustín de Salazar y Torres, concluido por sor Juana, y que no aparecía en este volumen:

Un Poema, que dejó sin acabar don Agustín de Salazar, y perficionó con graciosa propriedad la Poetisa, cuyo original guarda la estimación discreta de D. Francisco de las Heras [...], y por ser propio del primer Tomo, no le doy a la Estampa en este Libro, y se está imprimiendo, para representarse a sus Magestades (Fama, p. 125).

La obra inconclusa de Agustín de Salazar y Torres es El encanto es la hermosura y el hechizo sin hechizo. Con un final de Juan de Vera y Tassis fue publicada en 1681 y 1694 . Con el nombre de La segunda Celestina se relaciona la obra con un final escrito por sor Juana; de él habla Castorena y Ursúa. Esta versión, al parecer, en los últimos años nadie la había encontrado; resultó después que varios estudiosos tenían alguna suelta de La segunda Celestina, o sea, hay varias sueltas - fechadas y no- de la obra. Pues bien, entre junio de 1990 y abril de 1991 se suscitó una polémica sobre si sor Juana era autora o no del final de una versión de La segunda Celestina localizada por Guillermo Schmidhuber en la Universidad de Pennsylvania y publicada en julio de 1990 por la editorial Vuelta; los problemas de autoría giran sobre todo en relación con la fecha que acompaña a la suelta y con los años de su representación en España y en la Nueva España.

La versión de Schmidhuber — atribuida a sor Juana - impidió que otras «segundas Celestinas» aparecieran bajo coautoría de quien se convertiría en la gran dramaturga del siglo XVII novohispano. La suelta encontrada en Pennsylvania tiene la fecha de 1676; la loa que la antecede, la de 1675; Schmidhuber informa que hay otras dos sueltas en la Biblioteca Nacional de Madrid. De allí es una suelta, sin fecha, encontrada por Antonio Alatorre en 1985 y otra encontrada por Georgina Sabat de Rivers; esta última tiene la fecha de 1676, o sea, la misma fecha de una suelta mencionada antes por Thomas Austin O'Connor. La contienda en la que participaron algunos estudiosos ${ }^{6}$ duró varios meses y poco a poco se dejó de oír sin que se llegara a un acuerdo sobre si la suelta -motivo de la 
discusión- era o no de sor Juana ${ }^{7}$. Queda por lo pronto, y en el aire, sin definir si sor Juana escribió el final de la comedia antes o después de 1680. O la hizo antes de conocer a la condesa de Paredes, cuando estaba cerca del padre Núñez y empezaba a ser famosa por sus villancicos, o la hizo conociendo ya a la condesa de Paredes quien la relacionó estrecha y literariamente con España.

A la indefinición de este hallazgo, lo siguió un anuncio en 1993, cuando de nuevo Guillermo Schmidhuber publicó como hallazgo suyo la Protesta de la fee, y renovación de los Votos Religiosos, que hizo, y dejó escrita con su sangre la $M$. Juana Inés de la Cruz Monja Professa en S. Gerónimo de México, incluida en el Testamento Místico de una alma religiosa, que agonizante de amor por su Divino Esposo, moribunda ya, para morir al Mundo, instituye su querido, voluntario Heredero de todos sus bienes. Dispuesto por el M. R. P. Antonio Núñez, Prefecto que fue de la Congregación de la Puríssima. Se trata de un ejemplar del Testamento místico de Núñez, que Schmidhuber encontró en 1992 en la Universidad de Indiana ${ }^{8}$.

Schmidhuber se refiere a tres ejemplares de esta edición; dos — dice- están en la Biblioteca de la Universidad de Indiana y otro en la Hispanic Society de Nueva York. Ha de ser la edición de 1731, una de las reimpresiones conocidas del Testamento Místico de Núñez. Schmidhuber relaciona esta Protesta de la fe de sor Juana con el breve documento de Ratificación de votos de la monja, conservado en el Libro de Profesiones de San Jerónimo ${ }^{10}$; es el documento 412 de las Obras completas de Sor Juana Inés de la Cruz (vol. 4, p. 522). Sugiere que la Ratificación es síntesis de la Protesta de la fe.

Sin embargo, esta Protesta de la fe de sor Juana parecería relacionarse más con su nueva «Protestación», la protesta firmada el 5 de marzo de 1694 y conocida desde 1700, al publicarse la Fama y Obras pósthumas (pp. 124-126). La Protesta de la fe «recién localizada», más que la versión ampliada de la Ratificación (sin fecha), sería la síntesis de la «Protesta, que rubricada con su sangre, hizo de su Fe, y amor a Dios la Madre Juana Inés de la Cruz, al tiempo de abandonar

7 Véase Poot Herrera 1996. En la discusión sobre La segunda Celestina salió a colación precisamente y por Antonio Alatorre, uno de sus participantes más activos, el hallazgo de Martínez López; había sido citado antes por Trabulse (De la Maza 1980) y Bénassy-Berling (1982).

$8 \quad$ Manejo el artículo y la copia de la edición del Testamento místico y de la Protesta de la fe que aparece en la edición facsimilar del Segundo tomo de las obras de Sor Juana; la de 1693.

9 En cuanto al Testamento místico de Núñez, Schmidhuber menciona: «Impreso en México en dos ocasiones: 1707 y 1731 ». Y en la nota a pie dice «haber localizado tres ejemplares de la edición de 1737» (Schmidhuber 1995, p. 530); se ha de referir a la de 1731, a la mencionada arriba en el texto que es de la que ofrece copia (pp. 545-552). En la lista de las «Obras impresas» del padre Núñez que proporciona Josefina Muriel (1993) aparece el «Testamento mistico de una alma religiosa. Impr. en México, 1707» (p. 73).

10 El Libro de Profesiones se encuentra en la Biblioteca de la Universidad de Texas en Austin. 
los Estudios humanos, para proseguir desembarazada de este afecto, en el camino de la perfección»; es el documento 409 del volumen 4 de las Obras completas de Sor Juana Inés de la Cruz (pp. 418-419). Y de ser la nueva «Protestación» del 5 de marzo de 1694 -la incluida en la Fama y Obras pósthumas - la versión más amplia de la Protesta de la fe - la incluida en el Testamento místico-, entonces en Madrid y no en México se habría conocido primero oficialmente el documento.

Sin ser realmente un nuevo hallazgo esta protesta - puesto que sabían de ella y la conocían precisamente quienes conocen el Testamento místico ${ }^{11}$-, su publicación vuelve a juntar a Núñez de Miranda y a sor Juana Inés de la Cruz. Años habían pasado ya desde que la religiosa escribiera la carta a su confesor. ¿Volverían a encontrarse la monja jerónima y el padre jesuita en la década de los años noventa? Ya sabemos que estuvieron cerca entre sí —confesonario de por medio - en la década de los años setenta; que sor Juana - carta de por mediose despidió de él a principios de los ochenta; que ella estuvo lejos de él y cerca y muy apoyada por la virreina en los años ochenta. Sí, se sabía que sí, que el jesuita volvió a ser su confesor (Oviedo 1702, p. 36) y que para esas fechas dijo de sor Juana: «Es menester mortificarla, para que no se mortifique mucho, yéndola a la mano sus penitencias, porque no pierda la salud, y se inhabilite, porque Juana Inés no corre en la virtud, sino vuela» ${ }^{12}$. Los documentos de abjuración de sor Juana contextuarían este comentario alrededor de 1694 . Pero, ¿qué pasaría con ella muy a principios de los noventa? ¿Encuentro con qué personajes le depararía el destino?

A fines de 1690 se dio a conocer su Carta Atenagórica, en la que sor Juana discurría sobre las finezas de Cristo y ponía en crisis uno de los sermones del mandato del padre jesuita portugués Antonio Vieira. Papel protagonista tuvo en esta publicación el obispo de Puebla, a quien sor Juana — por este motivo- le escribió su Respuesta el primero de marzo de 1691; de esta carta, fechada y firmada en San Jerónimo, todos supieron al publicarse la Fama y Obras pósthumas en 1700. Lo que no se sabía era que, exactamente un mes antes de la Respuesta, otra carta se había firmado en San Jerónimo. Se supo en abril de 1995, en el tercer centenario de la muerte de sor Juana, cuando Elías Trabulse hizo pública la Carta que aviendo vista la Athenagórica que con tanto acierto dio a la estampa Sor

11 Ya concluido este trabajo, leo el recién publicado libro de Antonio Alatorre y Martha Lilia Tenorio; en su nota 23, pp. 132-133, mencionan como «hallazgo curioso» éste de Schmidhuber. Informan que el Testamento místico de Núnez, donde se incluye la Protesta de la fe de sor Juana, tuvo cinco ediciones. La primera es de 1701; la que ellos manejan es la de 1731; hay una de 1830. Dicen que la protesta incluida en el testamento es la versión abreviada de la protesta publicada en la Fama de 1700, la del 5 de marzo de 1694.

12 El énfasis aparece en la edición de la Fama (pp. 33-34); la foliación de estas páginas es de la edición facsimilar de la UNAM, 1995. 
Philotea de la Cruz, del convento de la Santíssima Trinidad de la Ciudad de los Ángeles, escribía Seraphina de Christo en el Convento de N. P. S. Gerónimo de México ${ }^{13}$.

Publicada en edición facsímile en 1996, y antecedida por otros escritos de Trabulse (1995a, b, c; 1996), se convierte en un documento importante respecto a las repercusiones de la Carta Atenagórica. Trabulse informa que en 1960 el padre jesuita Manuel Ignacio Pérez Alonso adquirió la Carta de Serafina de Cristo en Madrid, en una librería de libros viejos; en 1982 formó parte de una exposición de manuscritos en la Biblioteca Francisco Xavier Clavigero de la Universidad Iberoamericana. Allí la encontró el historiador, habló varias veces de ella, la estudió, hasta que la hizo pública en Toluca en abril de 1995.

Se trata de una carta que retoma la Carta Atenagórica, a personajes en ella involucrados y a involucrados con esos personajes; habla de «un soldado castellano» que ha impugnado la Atenagórica; que ese soldado es el mismo que ha arremetido en contra de Camila: la doncella de Virgilio como referencia; la relación con sor Juana hablando de Camila, «bien que sois de Camila fiel espejo». El soldado sería un lobo; Camila, una cordera, sor Juana. Según la carta, con Camila los Padres de la Iglesia - los de las finezas criticados en el sermón que sor Juana ha criticado_ - se han glorificado. Que fue un acierto publicar la Atenagórica, pero no el sermón de las finezas de Cristo porque su autor no había sido el padre Vieira. La carta -entreverada, extraña, con equívocos, con erratas, con varios «decires», con supuestos que han de haber entendido claramente quienes en ella participan como remitentes, como destinatarios, como destinatarios y como remitentes- está escrita en verso, en prosa, en español, en latín, de nuevo en prosa, por último en verso. Como la Atenagórica se firma en San Jerónimo.

Y se firma con el seudónimo de Serafina de Cristo. Para Elías Trabulse, Serafina es sor Juana que le escribe a Fernández de Santa Cruz; el soldado, el padre Núñez. Para Trabulse, también, sor Juana aclara no haber criticado a Vieira en su Crisis sobre un sermón - léase Carta Atenagórica- sino a Núñez. Con la noticia de la Carta de Serafina de Cristo aceptamos con Trabulse que Serafina fuera sor Juana; después, otorgándole la misma importancia a su interpretación y agradeciéndole la extraordinaria noticia, sugerimos que sor Juana podría ser autora material o intelectual de la carta; lo importante era -precisamente por la Carta de Serafina de Cristo, dada a conocer por Trabulse- que sor Juana no estaba sola, sino que tenía amigos (Poot Herrera 1998a, b) y que éstos la defenderían. En el muy reciente libro de Antonio Alatorre y Martha Lilia Tenorio (pp. 140-146), sus autores sugieren que Serafina de Cristo es Juan Ignacio Castorena y

13 Fue hecha pública oficialmente la tarde del martes 18 de abril en el Coloquio Internacional Sor Juana Inés de la Cruz y el pensamiento novohispano, celebrado del 17 al 21 de abril de 1995 en Toluca, Estado de México. 
Ursúa, y la carta va dirigida a sor Juana. Castorena y Ursúa —editor de la Fama y Obras pósthumas - precisamente la había defendido. No se sugiere quién pueda ser el «soldado».

Las noticias sobre la Carta de Serafina de Cristo coincidieron con otras noticias provenientes del Catálogo de textos marginados. Inquisición: siglo XVII. Antes de su publicación, apareció el trabajo de Ricardo Camarena -entonces investigador del proyecto-sobre un legajo de documentos que localizaron en el Archivo General de la Nación. Se trata de La fineza mayor, sermón que, impreso el 10 de marzo de 1691, leyó Francisco Xavier Palavicino — su autor- en San Jerónimo el 26 de enero de 1691. Palavicino habló también del «soldado» que había impugnado a sor Juana por su Carta Atenagórica. El enfrentamiento soldado vs. sor Juana fue consignado por el sermón de Palavicino y por la carta de Serafina en 1691. Lo supimos en 1995. Nuevas viejas relaciones fueron apareciendo alrededor de sor Juana.

Se sabía del sermón de Palavicino; lo que no se sabía era que —en alabanza de sor Juana - había sido acusado, censurado y prohibido por el Santo Tribunal de la Inquisición. De eso nos informó Camarena en 1995. Con la publicación del Catálogo de textos marginados. Inquisición: siglo XVII — a mediados de 1997se puso a disposición de los lectores el legajo de documentos y firmas inquisitoriales que van de la denuncia a la prohibición del sermón panegírico de Palavicino ${ }^{14}$. El sermón había sido aprobado por el capellán de San Jerónimo —el bachiller Juan de Gárate, quien oyó de viva voz a Palavicino- y por el fraile Rodrigo Galindo. Al primero le pidió la aprobación el virrey conde de Galve; al segundo, Diego de la Sierra, canónigo de la catedral, provisor y vicario del arzobispado. No obstante, fue denunciado - también desde catedral - y prohibido por la Santa Inquisición: lo denunció Alonso Alberto de Velasco y lo censuró negativamente el dominico Agustín Dorantes, quien consignó en su censura que el papel de un soldado había salido en contra de sor Juana, autora de la Carta Atenagórica. A sor Juana Palavicino había dedicado el sermón del que ahora él solicitaba que se prohibiera. La firma inquisitorial de Dorantes es del 25 de noviembre de 1691; un año antes el obispo de Puebla había dado su licencia para la publicación de la Carta Atenagórica, contra la que se pronunció el soldado, del que se defendió Palavicino diciendo que él no era, al que nombró Serafina de Cristo, seguramente el mismo impugnador de la Atenagórica al que sor Juana se refirió en la Respuesta.

A excepción de la conjetura de Trabulse, Núñez no aparece explícitamente en esos tejes y manejes de 1690 y 1691. Pero en el contexto social y personal sor

14 México, a[ño] de 1691. Autos sobre un sermón denunz[ia]do en este $S[$ anto] Off[ici]o, predicado en el conv[en] to de S[a]n Gerón[i]mo de esa ziu[da]d, por el 1[icencia]do d[o]n Fran[cis]co Xavier Palavicino. Archivo General de la Nación (México), Inquisición, vol. 525 ( $1^{\mathrm{a}}$. parte), exp. 4, fols. $252 \pi-260 \mathrm{r}$. 
Juana y Núñez estaban muy cerca; si sor Juana no es Serafina, podríamos pensar en algo que ya hemos dicho antes: «a no ser que en San Jerónimo [...] se inventara el nombre para dejar un testimonio más de que sor Juana — como Núñez de Miranda - tampoco estaba sola» (Poot Herrera 1998b, pp. 137-138). Entre las amistades de Núñez, y no vamos a mencionar precisamente al arzobispo Aguiar y Seixas ni al obispo Fernández de Santa Cruz, estaban sus «dichosos alumnos» (Oviedo 1702, p. 21): Alonso Alberto de Velasco y a Agustín Dorantes; uno -consultor del Santo Oficio- denunció el sermón de Palavicino en el que elogiaba a sor Juana; el otro —calificador inquisitorial— lo prohibió y se refirió a la monja más famosa de la Nueva España como «una mujer introducida a theóloga y escripturista». Así estaban las cosas en 1691.

¿Dejaría de escribir sor Juana después de su Respuesta de ese año? Los textos publicados en la Fama y Obras pósthumas dicen lo contrario; los Enigmas escritos a las monjas de La Casa del Placer podrían reafirmarlo y qué decir del inventario que Teresa Castelló Yturbide presentó en el Congreso Internacional Sor Juana y su mundo: una mirada actual, celebrado en la Universidad del Claustro de Sor Juana en noviembre de 1995. Es copia de 1843 de un inventario que se levantó en San Jerónimo después de la muerte de la monja; en una cuartilla se consigna que la monja jerónima siguió escribiendo «versos místicos y mundanos» - había quince legajos de escritos-y siguió estudiando hasta poco antes de morir. El inventario registra 180 volúmenes de obras selectas (véase Trabulse 1996, p. 26). Genio y escritura... Murió el domingo 17 de abril de 1695. Ya Núñez había muerto; hemos visto que su Testamento místico incluye una Protesta de la $f e$ de sor Juana; ambas de publicación póstuma.

Pues resulta que el 6 de junio de 1997, en el coloquio Sor Juana \& Vieira, trescientos años después, Elías Trabulse habló de una Protesta de la fe de la Monja profesa Sor Juana Inés de la Cruz, impresa por doña María de Benavides que hacía este tipo de trabajos al arzobispado. Informó Trabulse que esta protesta es una versión resumida de la del 5 de marzo de 1694; la primera fue hecha por mandato arzobispal; la segunda, impresa por el mismo mandato.

Según el historiador, fue publicada también en forma resumida -aunque más amplia- en el Testamento Mýstico de una alma religiosa del padre Núñez. Se refiere Trabulse a la edición de 1707, impresa por Miguel Ribera de Calderón, hijo de quien imprimiera la Protesta de la fe de 1695. Es decir, fue una adición posterior al Testamento místico de Núñez (Trabulse 1998, pp. 150-152). Esta explicación amplía y cambia lo que se había dicho respecto a la protesta de 1731 -mismo documento, otra reimpresión-; es decir, la Protesta de la Fe del 5 de marzo de 1694 - según Trabulse - fue hecha por sor Juana obligada por Aguiar y Seixas; Núñez no está mencionado. Al morir sor Juana, se resume y se imprime; es la que hace circular Aguiar y Seixas entre las monjas para que se enteraran que la de San Jerónimo había claudicado. Años después - menos resumida que la del 
95 pero menos amplia que la del 94 - pasa a formar parte del Testamento místico de Núñez. Trabulse maneja la edición de 1707, quien refiere también a la de 1731 que es la que encontró Schmidhuber y la que comentan Alatorre y Tenorio ${ }^{15}$.

Aguiar y Seixas ya estaba en plena acción desde 1693 cuando, según Trabulse, le confiscó sus bienes a la contadora de San Jerónimo y en 1694 la obligó a escribir los documentos de abjuración. Ésta - hasta hoy - última información de Trabulse es parte de un proceso de investigación que aún no concluye; lo que el historiador ha informado en las publicaciones que recogen sus conferencias han de ser fundamentadas históricamente: serán un eslabón más de sus ya tradicionales estudios sobre sor Juana.

La Protesta de la fe del 5 de marzo de 1694 pudo haber sido escrita por mandato de Aguiar y Seixas, como opina Trabulse; también pudo haber sido escrita a petición de Núñez de Miranda que volvió a ser confesor de sor Juana y haber sido resumida e incluida en su testamento. Protesta y testamento se publicaron cuando los dos habían muerto: él el 17 de febrero de 1695; ella el 17 de abril de 1695 . Una historia propia y común hay detrás de este padre jesuita y su hija espiritual. Les tocó vivir en la misma época y no fue casual que estuvieran cerca y lejos entre sí; en la misma ciudad que hicieron más «letrada». Él escribió villancicos; ella, los más famosos; él tenía el derecho eclesiástico de hablar de la finezas de Cristo, como nos lo informa María Águeda Méndez (1998); ella habló de las finezas a lo largo de sus escritos. Hay, entre los documentos que no publica Castorena y Ursúa en la Fama y Obras pósthumas, «Otros Discursos a las Finezas de Christo Señor nuestro» (p. 125). Además, corrieron riesgos similares. Por el proceso inquisitorial que se le hizo a Palavicino nos enteramos que el nombre de ella sí fue mencionado en la sede de la Santa Inquisición. María Águeda Méndez también nos informa - y ivaya hallazgo! - que Núñez de Miranda fue «un calificador calificado» (1997 y 1998) al ser denunciados no uno sino varios de sus discursos religiosos. Él salió ileso; el resultado inquisitorial que tuvo la fineza de Palavicino en su Sermón panegírico habla de cómo le fue a ella, y habría que seguir indagando. Pero, a diferencia de él, sor Juana estuvo a merced de otros prelados de la iglesia, nada menos que el arzobispo de México, el obispo de Puebla y el prefecto de la Congregación de la Purísima Concepción de la Virgen María, nadie menos que Núñez de Miranda, jesuita de gran poder en México.

Este poder no lo tuvo sor Juana pero su obra trascendió a la Nueva España, debido a su genio y a la suerte de haber tenido amistades dentro y fuera de allí. Falta mucho por decir de esas relaciones; los hallazgos de los últimos años ofrecen más relatos.

15 Bravo 1993, quien da el dato bibliográfico completo, y Muriel 1993, anotan la del año de 1707 que Trabulse conoce, lo mismo que la de 1731. Schmidhuber menciona la de 1707 y conoce la de 1731; Alatorre y Tenorio mencionan cinco ediciones; son los únicos que dicen que la de 1701 es la primera, conocen la de 1731 y mencionan una de 1830 . 


\section{BIBLIOGRAFÍA}

ALATORRE, Antonio. 1980. «Para leer la Fama y Obras pósthumas de Sor Juana Inés de la Cruz», Nueva Revista de Filología Hispánica, 29, pp. 428-508.

ALATORRE, Antonio. 1984. «Un soneto desconocido de Sor Juana», Vuelta, núm. 94, pp. 4-13.

ALATORRE, Antonio. 1987. «La Carta de Sor Juana al P. Núñez», Nueva Revista de Filología Hispánica, XXXV.2, pp. 591-673.

ALATORRE, Antonio y Martha Lilia TENORIO. 1988. Serafina y Sor Juana, México, El Colegio de México.

BÉNASSY-BERLING, Marie-Cécile. 1982, 1983. Humanisme et religion chez Sor Juana Inés de la Cruz, Paris, Éds. Hispaniques; Humanismo y religión en Sor Juana Inés de la Cruz, trad. de Laura LÓPEZ DE BELAIR, México, Universidad Nacional Autónoma de México.

BRAVO ARRIAGA, María Dolores. 1993. «La excepción y la regla: una monja según el discurso oficial y según Sor Juana», en Sara POOT-HERRERA (ed.), «Y diversa de mi misma / entre vuestras plumas ando». Homenaje internacional a Sor Juana Inés de la Cruz, México, El Colegio de México, pp. 36-41.

CAMARENA, Ricardo. 1995. "'Ruido con el Santo Oficio': Sor Juana y la censura inquisitorial», en (comp.), Margarita PEÑA Cuadernos de Sor Juana, México, Universidad Nacional Autónoma de México, pp. 283-306.

CRUZ, Juana Inés de la, sor. [ca. 1682]. Carta de la Madre Juana Inés de la Cruz escripta a el R. P. M. Antonio Núñez, de la Compañia de Jesús, [véanse los datos en Alatorre, 1987 y en TAPIA MÉNDEZ, 1981, 1986 y 1993].

CRUZ, Juana Inés de la, sor. [1689] 1995. Inundación Castálida de la Única Poetisa, Musa Décima, Soror Juana Inés de la Cruz, Religiosa Profesa en el Monasterio de San Jerónimo de la Imperial Ciudad de México. Que en varios metros, idiomas y estilos fertiliza varios asuntos, con elegantes, sutiles, claros, ingeniosos, útiles versos, para enseñanza, recreo y admiración. Dedícalos a la Excel.ma Señora. Señora D[oña] María Luisa Gonzaga Manrique de Lara, Condesa de Paredes, Marquesa de la Laguna, y los saca a luz D[on] Juan Camacho Gayna, Caballero del Orden de Santiago, Mayordomo y Caballerizo que fue de su Excelencia, Gobernador actual de la Ciudad del Puerto de Santa María, Madrid, Juan García Infanzón, edición facsimilar, presentación de Sergio FERNÁNDEZ, México, Universidad Nacional Autónoma de México. 
CRUZ, Juana Inés de la, sor. [1690] 1995. CARTA / ATHENAGORICA / DE LA MADRE / JUANA YNÉS / DE LA CRUZ/RELIGIOSA PROFESA DE VELO, 1 y Choro en el muy Religioso Convento de San Geró / nimo de la Ciudad de México cabeza de la / Nueva España. / QUE IMPRIME Y DEDICA A LA MISMA / SOR, / PHILOTEA DE LA CRUZ / Su estudiosa aficionada en el Convento de la San / tísima Trinidad de la Puebla / de los Angeles. / Con licencia en la Puebla de los Ángeles en la Imprentalde Diego Fernández de León. Año de 1690 / Hallárase este papel en la librería de Diego Fernández de León/debajo de el Portal de las Flores, edición facsimilar, estudio introductorio de Elías TRABULSE, México, Centro de Estudios de Historia de México Condumex.

CRUZ, Juana Inés de la, sor. [1692] 1995. SEGVNDO VOLVMEN / DE LAS OBRAS / DE SOROR / JVANA INÉS / DE LA CRVZ, / MONJA PROFESA EN EL MONASTERIO / DEL SEÑOR SAN GERÓNIMO / DE LA CIVDAD DE MÉXICO / DEDICADO POR SV MISMA AVTORA / A D. JVAN DE ORUE / Y ARBIETO / CAVALLERO DE LA ORDEN DE SANTIAGO. / Año 1692. / Con Privilegio, En Sevilla, por TOMAS LÓPEZ DE HARO, Impressor, y Mercader de Libros, edición facsimilar, pról. Margo GLANTZ, México, Universidad Nacional Autónoma de México.

CRUZ, Juana Inés de la, sor. [1693] 1995. Segundo tomo de las obras de Sor Juana Inés de la Cruz y La segunda Celestina, introducción de Fedro ARIAS DE LA CANAL, prólogo de Guillermo SCHMIDHUBER, México. [Contiene el prólogo a la Protesta de la fe de sor Juana Inés de la Cruz y la edición facsimilar de la Protesta de la fe de sor Juana Inés de la Cruz].

CRUZ, Juana Inés de la, sor. [1700] 1995. FAMA Y OBRAS / PÓSTHUMAS / DEL FÉNIX DE MÉXICO, / DÉCIMA MUSA, POETISA AMERICANA, / SOR JVANA INÉS DE LA CRUZ, RELIGIOSA PROFESSA / EN EL CONVENTO DE SAN GERÓNIMO / DE LA IMPERIAL CIVDAD DE MÉXICO / CONSÁGRALAS... EL DOCTOR DON JVAN IGNACIO / de Castorena y V, En MADRID: En la Imprenta de MANUEL RUIZ DE MURGA / a la Calle de la Habada. Año de 1700, edición facsimilar e introd., Antonio ALATORRE, México, Universidad Autónoma de México.

CRUZ, Juana Inés de la, sor. 1951, 1952, 1955, 1957. Obras completas. 4 vols., Alfonso MÉNDEZ PLANCARTE, ed., [vols. 1-3] y A. G. SALCEDA [vol. 4], México-Buenos Aires, Fondo de Cultura Económica.

CRUZ, Juana Inés de la, sor. 1994. Enigmas ofrecidos a La Casa del Placer, edición de Antonio ALATORRE, México, El Colegio de México.

CRUZ, Juana Inés de la, sor. [1691] 1996. Carta de Serafina de Cristo. 1691, edición facsimilar, introducción y transcripción paleográfica de Elías TRABULSE, Toluca, Instituto Mexiquense de Cultura. 
CRUZ, Juana Inés de la, sor y Agustín DE SALAZAR Y TORRES. 1990. La segunda Celestina. Una comedia perdida de Sor Juana, edición de Guillermo SCHMIDHUBER, México, Vuelta.

MARTÍNEZ LÓPEZ, Enrique. 1968. «Sor Juana Inés de la Cruz en Portugal: un desconocido homenaje y versos inéditos», Revista de Literatura, 33, pp. 5384.

MAZA, Francisco de la. 1980. Sor Juana Inés de la Cruz ante la historia (Biografías antiguas. La Fama de 1700. Noticias de 1667 a 1892), revisión y bibliografía de Elías TRABULSE, México, Universidad Nacional Autónoma de México.

MÉNDEZ, María Águeda, coord., 1997. Catálogo de textos marginados. Inquisición: siglo XVII, México, El Colegio de México, Archivo General de la Nación y Fondo Nacional para la Cultura y las Artes.

MÉNDEZ, María Águeda. 1997. «No es lo mismo ser calificador que calificado: una adición a la bibliografía del padre Antonio Núñez de Miranda, confesor de Sor Juana», en Martha Elena VENIER (ed.), Varia lingüistica y literaria, vol. 2: Literatura: de la Edad Media al siglo XVIII, México, El Colegio de México, pp. 397-413.

MÉNDEZ, María Águeda. 1998. «La prohibición y la conveniencia: Antonio Núñez de Miranda y la Inquisición novohispana», en K. Josu BIJUESCA y Pablo A. J. BRESCIA (eds.), Sor Juana \& Vieira, trescientos años después, Anejo de la revista Tinta, Santa Barbara, University of Santa Barbara, pp. 67-83.

MURIEL, Josefina. 1993. «Sor Juana Inés de la Cruz y los escritos del Padre Antonio Núñez de Miranda» en Sara POOT-HERRERA (ed.), «Y diversa de mí misma / entre vuestras plumas ando». Homenaje internacional a Sor Juana Inés de la Cruz, México, El Colegio de México, pp. 71-83.

NERVO, Amado [1910]. 1994. Juana de Asbaje, Introducción de Antonio ALATORRE, México, Consejo para la Cultura y las Artes, 1994.

O'CONNOR, Thomas Austin. 1992. «Los enredos de una pieza. El contexto histórico teatral de El encanto es la hermosura o La segunda Celestina de Salazar y Torres y Sor Juana», Literatura Mexicana, III.2, pp. 283-303.

OVIEDO, Juan Antonio de. 1702. Vida exemplar, heroicas virtudes y apostólicos misterios de el V. P. Antonio Núñez de Miranda de la Compañía de Jesús, México, Impr. Herederos de la viuda de Francisco Rodríguez Lupercio.

PALAVICINO, Francisco Xavier. 1691. La fineza mayor. En México, por Doña María de Benavides, viuda de Juan Ribera. / En el Empedradillo. Año de 1691, México, AGN, Inquisición, vol. 525 (1ª parte), exp. 3, fols. 261r-276v. 
PAZ, Octavio. 1982. Sor Juana Inés de la Cruz o Las trampas de la fe, México, Fondo de Cultura Económica, 1982.

POOT HERRERA, Sara. 1996. «La segunda Celestina, ¿de Salazar y Torres y sor Juana?», Mira de Amescua en candelero. Actas del Congreso Internacional sobre Mira de Amescua y el teatro español del siglo XVII, en Agustín DE LA GRANJA y Juan Antonio MARTÍNEZ BERBEL (eds.), Granada, Universidad de Granada, pp. 395-418.

POOT HERRERA, Sara. 1998a.»Las cartas de Sor Juana: públicas y privadas», en Margo GLANTZ (ed.), Sor Juana Inés de la Cruz y sus contemporáneos, Universidad Nacional Autónoma de México y Centro de Estudios de Historia de México Condumex, pp. 291-317.

POOT HERRERA, Sara. 1998b. «Una carta finamente calculada: la de Serafina de Cristo», en K. Josu BLJUESCA y Pablo A. J. BRESCIA (eds.), Sor Juana \& Vieira, trescientos años después, Anejo de la revista Tinta, Santa Barbara, University of Santa Barbara, pp. 127-141.

SABAT DE RIVERS, Georgina. 1992. «Los problemas de La segunda Celestina», Nueva Revista de Filología Española, XL.1, pp. 493-512.

SABAT DE RIVERS, Georgina. 1993. «Mujeres nobles del entorno de Sor Juana», en Sara POOT-HERRERA (ed.), «Y diversa de mi misma / entre vuestras plumas ando». Homenaje internacional a Sor Juana Inés de la Cruz, México, El Colegio de México, pp. 1-19.

SCHMIDHUBER, Guillermo. 1993. «Hallazgo y significación de un texto en prosa perteneciente a los últimos años de Sor Juana», Hispania, 76, pp. 189196.

TAPIA MÉNDEZ, Aureliano, ed. 1981, 1986, 1993. Autodefensa espiritual de Sor Juana, Monterrey, Universidad Autónoma de Nuevo León-Impresora Monterrey; "Carta de Sor Juana Inés de la Cruz a su confesor». Autodefensa espiritual, Monterrey, Impresora de Monterrey; Carta de Sor Juana Inés de la Cruz a su confesor. Autodefensa espiritual, prólogo de Octavio PAZ, Monterrey, Al Voleo El Troquel.

TRABULSE, Elías. 1995a. «La guerra de las finezas», en la Memoria del Coloquio Internacional Sor Juana Inés de la Cruz y el Pensamiento Novohispano. 1995, Toluca, Instituto Mexiquense de Cultura y Universidad Autónoma del Estado de México, pp. 483-493.

TRABULSE, Elías. 1995b. El enigma de Serafina de Cristo. Acerca de un manuscrito inédito de Sor Juana Inés de la Cruz (1691), Toluca, Instituto Mexiquense de Cultura. 
TRABULSE, Elías. 1995c. Los años finales de Sor Juana: una interpretación (1688-1695), México, Centro de Estudios de Historia de México Condumex, 1995.

TRABULSE, Elías. 1996. La memoria transfigurada. Tres imágenes históricas de Sor Juana, México, Universidad del Claustro de Sor Juana.

TRABULSE, Elías, ed. 1997. Carta q[ue] aviendo visto la Athenagórica q[ue] con tanto acierto dio a la estampa Sor Philotea de la Cruz del Convento de la Santíssima Trinidad de la ciudad de Los Ángeles escribía Seraphina de Christo en el Convento de N. P. S. Gerónimo de México, pról., Sara POOTHERRERA, Los Angeles, Aldan.

TRABULSE, Elías. 1998. «El silencio final de Sor Juana», en K. Josu BIJUESCA y Pablo A. J. BRESCIA (eds.), Sor Juana \& Vieira, trescientos años después, Anejo de la revista Tinta, Santa Barbara, University of Santa Barbara, pp. 143-156. 